\title{
Partial molecular characterization of the Nile tilapia (Oreochromis niloticus) $\alpha$-cardiac muscle actin gene and its relationship to actin isoforms of other fish species
}

\author{
Adriane P. Wasko ${ }^{1}$, Fábio E. Severino ${ }^{1}$, Flávia T. Presti ${ }^{2}$, Andréia B. Poletto ${ }^{2}$ and Cesar Martins ${ }^{2}$ \\ ${ }^{I}$ Departamento de Genética, Instituto de Biociências, Universidade Estadual Paulista, Botucatu, SP, Brazil. \\ ${ }^{2}$ Departamento de Morfologia, Instituto de Biociências, Universidade Estadual Paulista, Botucatu, SP, \\ Brazil.
}

\begin{abstract}
An alpha actin gene segment, isolated from Nile tilapia (Oreochromis niloticus), was characterized by nucleotide sequencing, predicted amino acid sequence and Southern blot hybridization. Genomic DNA amplification resulted in a 1063-bp fragment corresponding to a partial $\alpha$-cardiac muscle actin gene containing exons 3 to 6 . Southern blot analysis of the restriction-digested DNA revealed that the Nile tilapia genome contains multiple muscle actin isoforms. Although comparison of the nucleotide sequence, amino acid residues and exon-intron organization of the isolated actin gene with those of other vertebrates showed a high level of identity, diagnostic amino acid residues can still be correlated to distinct actin genes in fish species.
\end{abstract}

Key words: actin gene, amino acid residues, gene structure, Nile tilapia, nucleotide sequence, Oreochromis niloticus

Received: August 24, 2006; Accepted: February 12, 2007.

Actins are highly conserved proteins that are key components of eukaryotic cells and play important roles in the maintenance of the cytoskeletal structure, cell motility and division, intracellular movements and contractile processes (Clarke and Spudich, 1977). Genes encoding these proteins can occur in single copies, as in the fungi Saccharomyces cerevisiae and most green algae, or in multiple copies, as in seed plants and animals (Vandekerckhove and Weber, 1984; Bhattacharya et al., 2000). The genome of higher vertebrate species usually contains six different actin genes - four of these genes code for muscle isoforms $(\alpha$-skeletal, $\alpha$-cardiac, $\alpha$-vascular and $\gamma$-enteric) and two other genes code for the $\beta$ - and $\gamma$-cytoplasmic types (Vandekerckhove and Weber, 1979; Kusakabe et al., 1997). Despite the fact that these actin gene isoforms generally present a high degree of amino acid sequence homology (Alonso et al., 1986; Miwa et al., 1991), they can exhibit distinct tissue and developmental stage-specific patterns of expression (Venkatesh et al., 1996).

Data already exists on the evolution of mammalian actins but the evolutionary origin, organization and diversity of these genes in lower vertebrates, especially fish, still

Send correspondence to Cesar Martins. Departamento de Morfologia, Instituto de Biociências, Universidade Estadual Paulista, Campus de Botucatu, 18618-000 Botucatu, SP, Brazil. E-mail: cmartins@ibb.unesp.br. needs to be elucidated. The Nile tilapia (Oreochromis niloticus, L. 1766) represents one of the most important food fish species that have been intensively exploited in tropical and subtropical aquaculture (Pullin, 1991). Due to its economic importance, fundamental and applied biology studies on this fish may result in data useful for formulating more efficient management strategies. In this paper we report the isolation and partial characterization of an actin gene from $O$. niloticus, this work having been carried out not only to improve the molecular data on this species but also to provide a better understanding of the organization of the actin multigene family in fish genomes.

Total genomic DNA was isolated from the caudal or anal fins of $O$. niloticus using a TNES-urea-digestion buffer as described in Wasko et al. (2003) and further quantified in a spectrophotometer (BioPhotometer 6131, Eppendorf). Polymerase chain reaction (PCR) amplification of genomic DNA was performed using the primer set ActinF1 (5'-GTA TTG TGC TGG ACT CTG GTG-3') and ActinR1 (5'-GAA GCA CTT GCG GTG GAC GAT-3'), designed from the $\alpha$-actin gene sequence described for the fish Ictalurus punctatus (Kim et al., 2000) to amplify exons 3-6. Each PCR reaction mixture contained 150 pmoles of each primer, $\sim 100 \mathrm{ng}$ of genomic DNA, 1x Taq buffer, $200 \mu \mathrm{M}$ of dNTPs and 1 unit of Taq DNA polymerase (Invitrogen) in a final reaction volume of $25 \mu \mathrm{L}$. Cycling times were 
2 min at $95^{\circ} \mathrm{C}$ followed by 34 cycles of $30 \mathrm{~s}$ at $95^{\circ} \mathrm{C}$ (denaturation), $30 \mathrm{~s}$ at $55^{\circ} \mathrm{C}$ (annealing) and $1 \mathrm{~min}$ at $72^{\circ} \mathrm{C}$ (elongation) plus a final 5 min extension at $72{ }^{\circ} \mathrm{C}$. The PCR products were visualized using $1 \%(\mathrm{w} / \mathrm{v})$ agarose gel electrophoresis and then ligated into a pGEM-T vector (Promega) and used to transform competent $E$. coli strain $\mathrm{DH} 5 \alpha$ cells (Invitrogen Life Technologies). Clones were sequenced on an ABI 377 Automated DNA Sequencer (Applied Biosystems) and sequence alignments were performed using the ClustalW program (Thompson et al., 1994). Nucleic acid sequences were subjected to BLAST/N (Altschul et al., 1990) searches at the National Center for Biotechnology Information (NCBI). Deduced amino acid sequences were obtained by the Gene Runner software version 3.05 (Hastings Software, Inc.).

Genomic DNA $(8 \mu \mathrm{g})$ from $O$. niloticus was digested overnight with 45 units of DraI, BamHI, HincII, HindIII or $B g l I I$ endonucleases and the products separated by electrophoresis on $1 \%(\mathrm{w} / \mathrm{v})$ agarose gel and Southern-transferred to a Hybond-N nylon membrane (Southern, 1975). The immobilized DNA was probed with the cloned $O$. niloticus actin gene segment, described above, using the chemiluminescent kits Alkphos Direct Labelling Reagents and Gene Images (Amersham Bioscience).

The PCR amplification and agarose gel electrophoresis resulted in a single band of approximately 1000 base pairs (bp). Nucleotide sequencing analysis of positive clones of PCR-fragments revealed a DNA segment composed of 1063-bp. Searches of public nucleotide sequence databases and amino acid identities at diagnostic positions indicated that the O. niloticus DNA fragment had high sim- ilarity (> 84\%) to the $\alpha$-muscle actin of mammals, birds, reptilians, amphibians and several fish species, and corresponded to exons $3,4,5$, and 6 of the $\alpha$-muscle actin gene. However, an even higher degree of identity occurred with pufferfish (Fugu rubripes) $\alpha$-cardiac muscle actin coding regions, $89.9 \%$ for exon 3, $91.3 \%$ for exon 4 and $90 \%$ for exons 5 and 6. Database searches also revealed that the isolated actin fragment of $O$. niloticus presented a high similarity $(>81 \%)$ with $\beta$-actin isoforms of several other vertebrates. This high nucleotide identity among different muscle ( $\alpha$-actins) and cytoplasmic ( $\gamma$ - and $\beta$-actin) isoforms of several organisms demonstrates that actin genes have maintained their basal structure during species diversification as a consequence of the importance of such proteins cell structure and function.

Our deduced amino acid sequence of the $O$. niloticus $\alpha$-cardiac muscle actin corresponding to residues 153-377 were aligned with the deduced amino acid residues of an $\alpha$-actin isoform and a $\beta$-cytoplasmic actin of Oreochromis mossambicus, another tilapia species, obtained through Blast searches (Figure 1). Although $O$. niloticus and $O$. mossambicus presented several nucleotide differences in exons $3,4,5$, and 6 of the alpha actin isoform, their deduced amino acid sequences showed a high degree of similarity $(97.9 \%)$ because most of the nucleotide variations were synonymous substitutions (SNS). We found that the $\alpha$ and $\beta$ actin types of the genus Oreochromis differ by the amino acid substitutions Leu/Met-155, Met/Leu-178, Val/Thr203, Asn/Gln-227, Ala/Gly-230, Thr/Ala-262, Ile/Leu269, Ala/Thr-280, Ile/Val-289, Ala/Ser-367. Except for

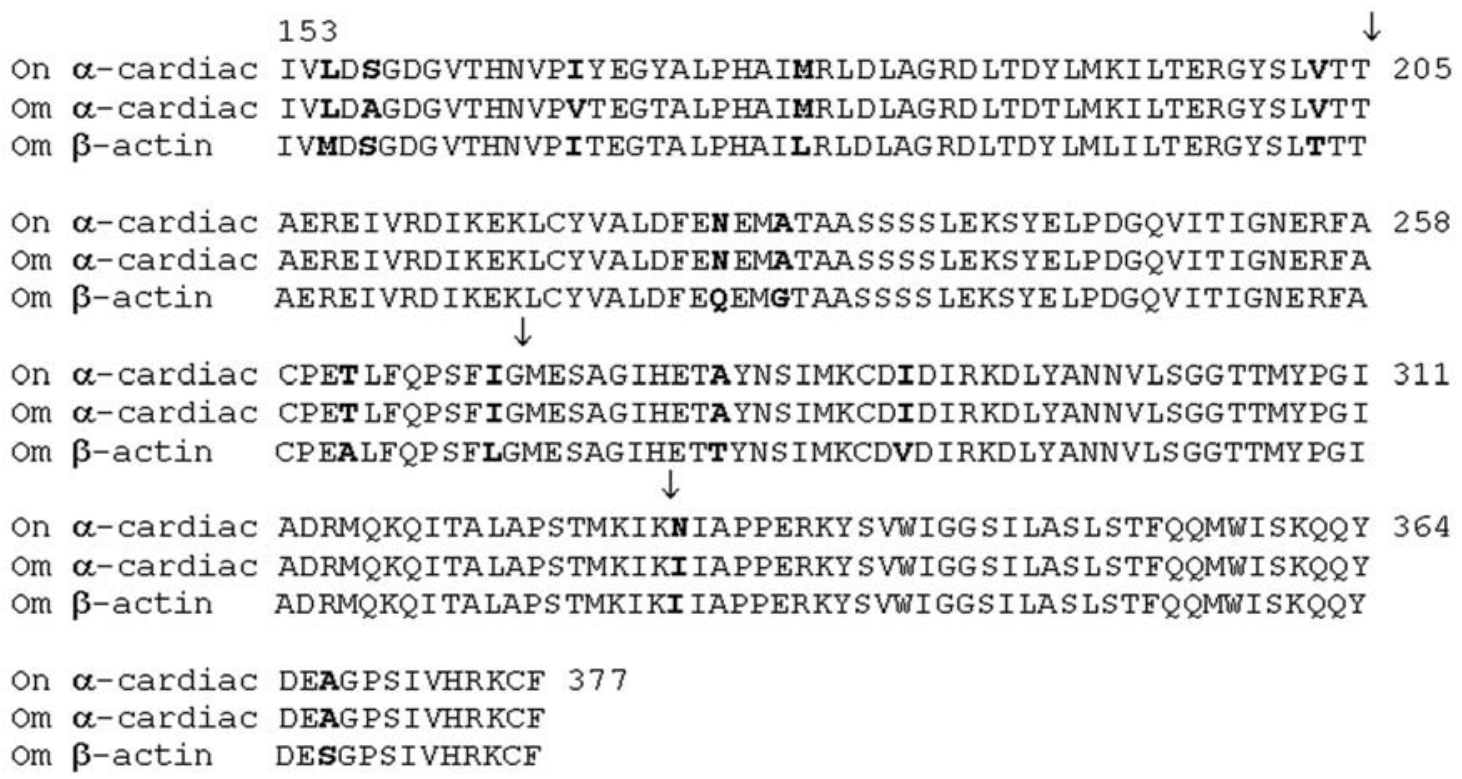

Figure 1 - Alignment of deduced amino acid sequences of the partial $\alpha$-cardiac muscle actin gene of the Nile tilapia Oreochromis niloticus (On $\alpha$-cardiac, present work), the partial $\alpha$-cardiac actin gene of Oreochromis mossambicus (Om $\alpha$-cardiac (GenBank AB037866), Kazuharu Takeuchi) and the partial $\beta$-actin gene of O. mossambicus (Om $\beta$-actin (GenBank AB037865), Kazuharu Takeuchi). Differences in the amino acid residues are shown in boldface type. Arrows indicate intron positions. 
Ala/Gly-230, all of these differences also occur between the $\alpha$ and $\beta$ cytoplasmic actin isoforms of $F$. rubripes (Venkatesh et al., 1996) and seem to represent diagnostic amino acid residues. Moreover, we also found Ser/Ala-157, Ile/Val-167 and Asn/Ile-331 substitutions between the $\alpha$-cardiac muscle actin of $O$. niloticus and the $\alpha$-muscle actin of $O$. mossambicus. Since Ala and Val substitutions at the amino acid residues 157 and 167, respectively, have already been described for $\alpha$-skeletal muscle actin isoforms of other fish species (Venkatesh et al., 1996; Morita, 2000), it seems probable that the $O$. mossambicus muscle actin corresponds to a skeletal isoform.

Southern blot results of $O$. niloticus genomic DNA digested with the DraI, BamHI, HincII, HindIII or BglII and hybridized with the $O$. niloticus 1063-bp $\alpha$-cardiac muscle actin gene segment isolated by us are shown in Figure 2. The restriction enzymes were chosen because they do not cleave inside the isolated actin gene segment. We found that $\mathrm{Dra \textrm {I }}$ and $B g l \mathrm{II}$ generated multiple bands that were mostly larger than 1600-bp, suggesting that each band probably corresponded to a different actin gene of this

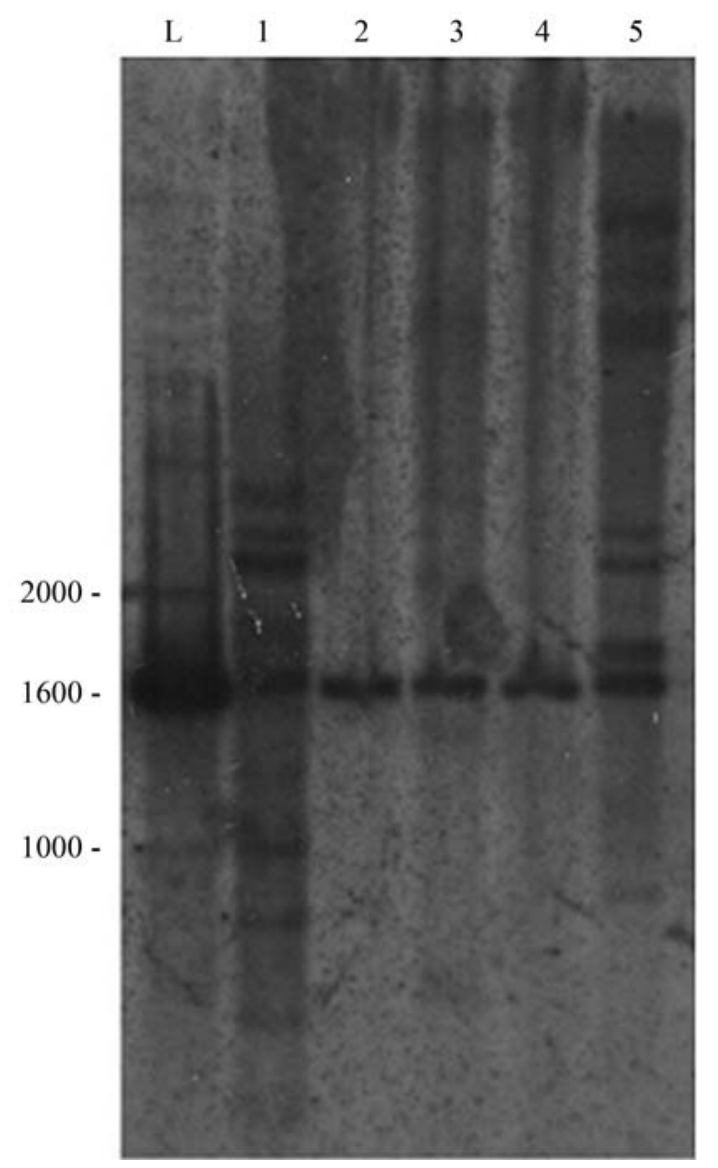

Figure 2 - Southern blot hybridization of genomic DNA of Oreochromis niloticus digested with the restriction enzymes (1) DraI, (2) BamHI, (3) HincII, (4) HindIII, and (5) BglII. The hybridization probe corresponds to the isolated $O$. niloticus $\alpha$-cardiac actin gene fragment. $\mathrm{L}=$ molecular weight marker in bp. multigene family. Since $\alpha$-actins and $\beta$-actins display high similarity $(>80 \%)$ in the exon regions, it is probable that some of the faint bands observed by us after membrane hybridization corresponded to $\beta$-actin genes. The presence of only one approximately 1600 -bp band after cleavage with BamHI, HincII, HindIII indicates that the restriction sites of these enzymes are exclusive to $\alpha$-cardiac actin genes. The Southern blot hybridization results also show that actin genes are dispersed throughout the $O$. niloticus genome instead of being tandemly organized.

The high degree of similarity among the nucleotide sequence and amino acid residues of the $\alpha$-cardiac actin gene of $O$. niloticus and those of other vertebrate species is, unsurprisingly, not only a consequence of the narrow evolutionary divergence between several species but is also due to the origin of the actin genes. It seems that actin isoforms are encoded by a set of structurally related genes that developed as a consequence of gene duplication followed by functional divergence (Hightower and Meagher, 1986), resulting in highly conserved proteins. However, despite the high degree of identity even between distinct actin types we have identified diagnostic amino acid residues that are useful not only in distinguishing actin genes but could also be used as potential genus-specific or speciesspecific markers.

\section{Acknowledgments}

This research was supported by grants from the Brazilian agencies Fundação de Amparo à Pesquisa do Estado de São Paulo (FAPESP) and Conselho Nacional de Desenvolvimento Científico e Tecnológico (CNPq).

\section{References}

Alonso S, Minty A, Bourlet Y and Bauckingham M (1986) Comparison of 3 actin-coding sequences in the mouse - Evolutionary relationships between the actin genes of warmblooded vertebrates. J Mol Evol 23:11-22.

Altschul SF, Gish W, Miller W, Myers EW and Lipman DJ (1990) Basic local alignment search tool. J Mol Biol 215:403-410.

Bhattacharya D, Aubry J, Twait EC and Jurk S (2000) Actin gene duplication and the evolution of morphological complexity in land plants. J Phycol 36:813-820.

Clarke M and Spudich JA (1977) Non-muscle contractile proteins - Role of actin and myosin in cell motility and shape determination. Annu Rev Biochem 46:797-822.

Hightower RC and Meagher RB (1986) The molecular evolution of actin. Genetics 114:315-332.

Kim S, Karsi A, Dunham RA and Liu Z (2000) The skeletal muscle $\alpha$-actin gene of channel catfish (Ictalurus punctatus) and its association with piscine specific SINE elements. Gene 252:173-181.

Kusakabe T, Araki I, Satoh N and Jeffrey WR (1997) Evolution of chordate actin genes: Evidence from genomic organization and amino acid sequences. J Mol Evol 44:289-298.

Miwa T, Manabe Y, Kurokawa K, Kamada S, Kanda N, Bruns G, Ueyama H and Kakunaga T (1991) Structure, chromosome 
location, and expression of the human smooth muscle (enteric type) gamma-actin gene: Evolution of six human actin genes. Mol Cell Biol 11:3296-3306.

Morita T (2000). Amino acid sequences of $\alpha$-skeletal muscle actin isoforms in two species of rattail fish, Coryphaenoides acrolepis and Coryphaenoides cinereus. Fish Sci 66:11501157.

Pullin RSV (1991) Cichlids in aquaculture. In: Keenleyside MHA (ed) Cichlid Fishes: Behaviour, Ecology and Evolution. Chapman \& Hall, New York, pp 280-309.

Southern EM (1975) Detection of specific sequences among DNA fragments separated by gel-electrophoresis. J Mol Biol 98:503-517.

Thompson JD, Higgins DG and Gibson TJ (1994) Clustal W: Improving the sensitivity of progressive multiple sequence alignment through sequence weighting, position-specific gap penalties and weight matrix choice. Nucleic Acids Res 22:4673-4680.
Vandekerckhove J and Weber K (1979) The complete amino acid sequence of actins from bovine aorta, bovine heart, bovine fast skeletal muscle, and rabbit slow skeletal muscle: A protein-chemical analysis of muscle actin differentiation. Differentiation 14:123-133.

Vandekerckhove J and Weber K (1984) Chordate muscle actin differ distinctly from invertebrate muscle actins: The evolution of the different vertebrate muscle actins. J Mol Biol 179:391-413.

Venkatesh B, Tay BH, Elgar G and Brenner S (1996) Isolation, characterization and evolution of nine pufferfish (Fugu rubripes) actin genes. J Mol Biol 259:655-665.

Wasko AP, Martins C, Oliveira C and Foresti F (2003) Nondestructive genetic sampling in fish. An improved method for DNA extraction from fish fins and scales. Hereditas 138:161-165.

\section{Internet Resource}

National Center for Biotechnology Information (NCBI), http:// www.ncbi.nlm.nih.gov/blast.

Assistant Editor: Klaus Hartfelder 